\title{
REVIEW
}

\section{Challenges in idiopathic pulmonary fibrosis trials: the point on end-points}

\section{Albera}

ABSTRACT: Idiopathic pulmonary fibrosis (IPF) is the most common of the idiopathic interstitial pneumonias and is associated with both a variable clinical course and a poor prognosis. Investigators involved in clinical trials and clinicians reviewing the IPF literature are confronted with daunting challenges in selecting reliable outcome measures, interpreting the clinical and statistical importance of these findings, and applying this knowledge to the clinical care of their patients. In order to evaluate the efficacy of new treatment regimens, a number of studies have been performed, employing a range of clinical and surrogate end-points. In most studies, the primary end-point consists of a single outcome measure. A desirable single clinical end-point for IPF should be reliable, valid, responsive to changes in disease status, clinically meaningful, predictive of clinical outcome and responsive to treatment effect of a given intervention. Proper consideration and effective choice of outcome measures used in IPF studies will help establish effective and achievable drug development programmes and will enable clinicians and investigators to make informed critical decisions in recommending a treatment regimen to their IPF patients.

KEYWORDS: End-points, forced vital capacity, idiopathic pulmonary fibrosis, idiopathic pulmonary fibrosis trials, 6-min walk test

I diopathic pulmonary fibrosis (IPF) is a progressive, life-threatening interstitial lung disease (ILD). It has a significant impact on the quality of life of patients, and the prognosis is worse than most other ILDs [1-3].

In IPF, lung parenchyma architecture is irreversibly disrupted with resulting functional impairment [2]. No cases of spontaneous regression have been observed; presumably because there is no way the fibrotic change can be reversed. However, within this framework, there is a high degree of inter-individual variability with respect to disease extent, disease progression and survival time [2, 4]. One study has shown that the clinical course of patients with mild-to-moderate IPF is characterised by: 1) minimal physiological deterioration as measured by forced vital capacity (FVC), diffusing capacity of the lung for carbon monoxide $(\mathrm{DL}, \mathrm{CO})$ and alveolar-arterial oxygen tension difference $\left(\mathrm{PA}-\mathrm{a}, \mathrm{O}_{2}\right) ; 2$ ) frequent hospitalisations for respiratory disorders; and 3) an acute, rapid and fatal deterioration of lung disease in almost half of the patients who die from an IPF-related cause [5]. The marked variability in the extent and rate of disease progression from one individual to the next means that early and accurate diagnosis and early referral may give the best chance of optimal therapy, as response rates may be higher when treatment is initiated before the development of irreversible fibrosis [1, 2]. As the diagnosis of definite IPF is frequently made without surgical lung biopsy, it is relevant to ask whether the method of diagnosis could influence treatment outcomes, i.e. whether it could act as bias for any end-point. It has been demonstrated in a welldefined cohort of IPF patients that neither disease severity, as assessed by baseline FVC \% predicted, nor rate of disease progression, as assessed by change in FVC \% predicted, were significantly different in patients who had a surgical lung biopsy compared with those who did not. Moreover, the treatment effect for pirfenidone was similar in patients with and without a surgical lung biopsy [6].

\section{PRIMARY END-POINTS}

Reliable, objective parameters to assess disease progression and treatment response are currently poorly defined and not fully validated. Thresholds for change in several lung function parameters
CORRESPONDENCE

C. Albera

Dept of Clinical and Biological

Sciences

Interstitial and Rare Diseases Unit University of Turin

San Luigi Gonzaga Medical School Regione Gonzole 10

10043 Orbassano

Turin

Italy

E-mail carlo.albera@unito.it

Received:

Feb 142011

Accepted after revision:

April 042011

PROVENANCE

Publication of this peer-reviewed article was supported by InterMune Inc., Brisbane, CA, USA (article sponsor, European Respiratory Review issue 121) 
(total lung capacity, FVC, single-breath $\mathrm{DL}, \mathrm{CO}$, arterial oxygen pressure, $\mathrm{PA}-\mathrm{a}, \mathrm{O}_{2}$ and oxygen saturation) have been identified as representative of a favourable or improved response to therapy in patients with IPF [2]. However, there are insufficient data to establish whether these are the most reliable and valid measurements of therapeutic efficacy [7]. Attempts to identify clinical and surrogate end-points for IPF clinical trials have either failed or merely provided positive signals, generating hypotheses requiring further investigation [7-10]. In the past 20 yrs many clinical trials have been conducted to evaluate the efficacy and safety of different and innovative drugs in the treatment of IPF. Table 1 demonstrates the heterogeneity of primary end-points used in these trials [8, 9, 11-18]. Studies have generally measured lung function as this is the most valid end-point. However, the challenges involved in choosing the most appropriate outcome have not been discussed in these papers.

Regulatory guidance from the US Food and Drug Administration (FDA) has identified several key parameters with regard to end-points [19]. The FDA assessment acknowledges that interpreting change in lung function in IPF is challenging, but proposes that a categorical reduction in FVC of $\geqslant 10 \%$ could be regarded as clinically meaningful based on available evidence. Mortality is identified as the ideal and most compelling primary end-point in clinical trials, particularly as there are no well-established or validated surrogates for mortality in IPF. However, the importance of other clinically meaningful end-points is highlighted, including: survival; survival plus disease progression (composite end-point); preservation of lung function; dyspnoea; functional status; and quality of life. It is important to note that mortality findings should be supportive of other clinical end-points [19].

\section{IPF CLINICAL END-POINTS: DESIRABLE CHARACTERISTICS}

A desirable single clinical end-point for IPF should be reliable, valid, responsive to changes in disease status, clinically

\begin{tabular}{|c|c|c|c|c|c|c|c|}
\hline TABLE 1 & \multicolumn{7}{|c|}{$\begin{array}{l}\text { Primary end-points of idiopathic pulmonary } \\
\text { fibrosis clinical trials performed in the last } 20 \text { yrs }\end{array}$} \\
\hline \multicolumn{2}{|c|}{ NobLE et al. [11] } & FVC & & & & & \\
\hline \multicolumn{2}{|c|}{ TANIGUCHI et al. [12] } & & VC & & & & \\
\hline \multicolumn{2}{|c|}{ DanieLs et al. [13] } & & & & & & PFS $^{\#}$ \\
\hline \multicolumn{2}{|c|}{ KING et al. [14] } & & & & & & Survival \\
\hline \multicolumn{2}{|c|}{ RAGHU et al. [15] } & FVC & & $D \mathrm{~L}, \mathrm{CO}$ & $\mathrm{Pa}_{1} \mathrm{O}_{2}$ & & \\
\hline \multicolumn{2}{|c|}{ KING et al. [16] } & & & & & $6 \mathrm{MWT}$ & \\
\hline \multicolumn{2}{|c|}{ Kuвo et al. [17] } & & & & & & Survival \\
\hline \multicolumn{2}{|c|}{ DEmedTs et al. [18] } & & VC & $D \mathrm{~L}, \mathrm{CO}$ & & & \\
\hline \multicolumn{2}{|c|}{ Azuma et al. [8] } & & & & 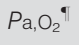 & $6 \mathrm{MWT}^{\circ}$ & \\
\hline \multicolumn{2}{|c|}{ RAGHU et al. [9] } & & & & & & $\mathrm{PFS}^{+}$ \\
\hline
\end{tabular}

FVC: forced vital capacity; VC: vital capacity; $D L, C O$ : diffusing capacity of the lung for carbon monoxide; $\mathrm{Pa}_{2} \mathrm{O}_{2}$ : arterial oxygen tension; $6 \mathrm{MWT}$ : 6-min walk test; PFS: progression-free survival. ${ }^{\#}$ : time to disease progression defined as decline in FVC (\%) from baseline predicted FVC or death; ": lowest arterial oxygen saturation measured by pulse oximetry during $6 \mathrm{MWT} ;{ }^{+}$: defined as $\geqslant 10 \%$ decline from baseline of predicted $\mathrm{VC}$ or an increase $\geqslant 5 \mathrm{mmHg}$ in the alveolar-arterial oxygen tension difference at rest. meaningful, predictive of clinical outcome and responsive to treatment effect of a given intervention.

\section{Reliability}

A reliable clinical end-point is one that offers stability of measurement. The distance walked at the 6-min walk test (6MWT) is a practical, simple assessment of self-paced exercise capacity [20]. The test is very reliable in patients with IPF, showing only small variation when repeated in the same subject over a short period of time (coefficient of variation $4.2 \%$ ) [21]. The 6MWT is well established as a surrogate endpoint in clinical studies of pulmonary arterial hypertension (PAH) [22]. Recently, the reliability of the 6MWT in IPF was assessed using data from the largest clinical trial to date (INSPIRE (effect of interferon $\gamma-1 b$ on survival in patients with idiopathic pulmonary fibrosis); $n=822$ ). Comparison of the $6 \mathrm{MWT}$ on two separate days (mean interval 24 days) demonstrated high reliability (intraclass correlation coefficient 0.82 ; $\mathrm{p}<0.001)$ [23].

\section{Validity and responsiveness to changes in disease status}

A good end-point should correlate well with other measures of disease status (validity) and should be responsive to changes in disease status. FVC is widely used and accepted as a clinically meaningful measure of IPF disease status [2]. Recent data show that when FVC and 6MWT are assessed for validity and responsiveness using other functional parameters $(D \mathrm{~L}, \mathrm{CO}$, the St George's Respiratory Questionnaire score and the University of California, San Diego, Shortness of Breath Questionnaire score), the correlations are statistically significant $(p<0.001)$, if rather weak (figs 1 and 2) [23, 24].

\section{Ability to show clinically meaningful difference}

One of the key challenges that the investigator faces when selecting primary outcome measures, is determining the significance of any observed differences (statistical significance versus clinical relevance) and communicating the same to clinicians who will be applying the trial results. Minimal clinically important difference (MCID) is defined as the smallest difference in an outcome measure that patients would perceive to be important and that would lead a clinician to consider a change in a patient's status [25]. Estimated MCID for FVC is approximately three to five units and for 6MWT is 23-45 m [23, 24].

\section{Ability to predict clinical outcome}

A valid end-point should correlate reasonably well to clinical outcome (survival). A number of end-points have been found to be predictors of mortality in published IPF studies, including: FVC [7, 26-29]; DL,CO (\% pred) [7, 26, 29]; alveolar-arterial gradient [7, 27]; dyspnoea [27]; 6MWT desaturation $(<88 \%)$ [30]; 6MWT distance [23, 31, 32], highresolution computed tomography (HRCT) fibrosis score [33]; HRCT pattern (typical/atypical) [34]; and respiratory hospitalisation [1]. Of these, FVC and 6MWT can be considered as the best predictors of mortality at baseline in IPF. Published literature has identified a categorical reduction of $\geqslant 10 \%$ in FVC as both reliable and predictive of mortality, and is associated with a greater than two-fold increase in the risk of death $[7,27,28]$. It has also been noted that a change in $6 \mathrm{MWT}$ (walked distance in $\mathrm{m}$ ) is highly predictive of mortality; 

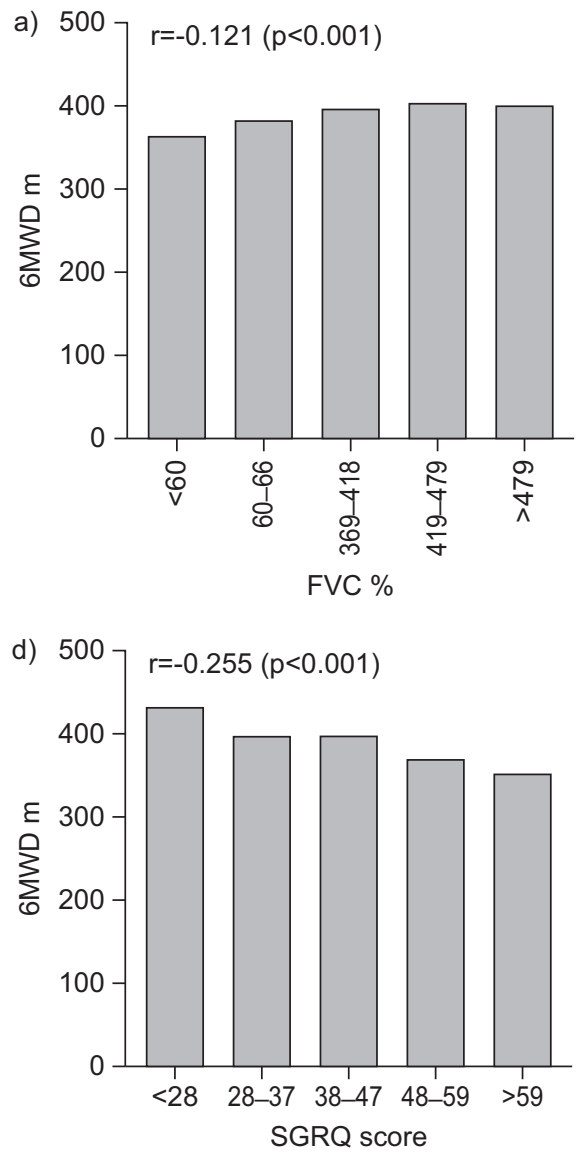
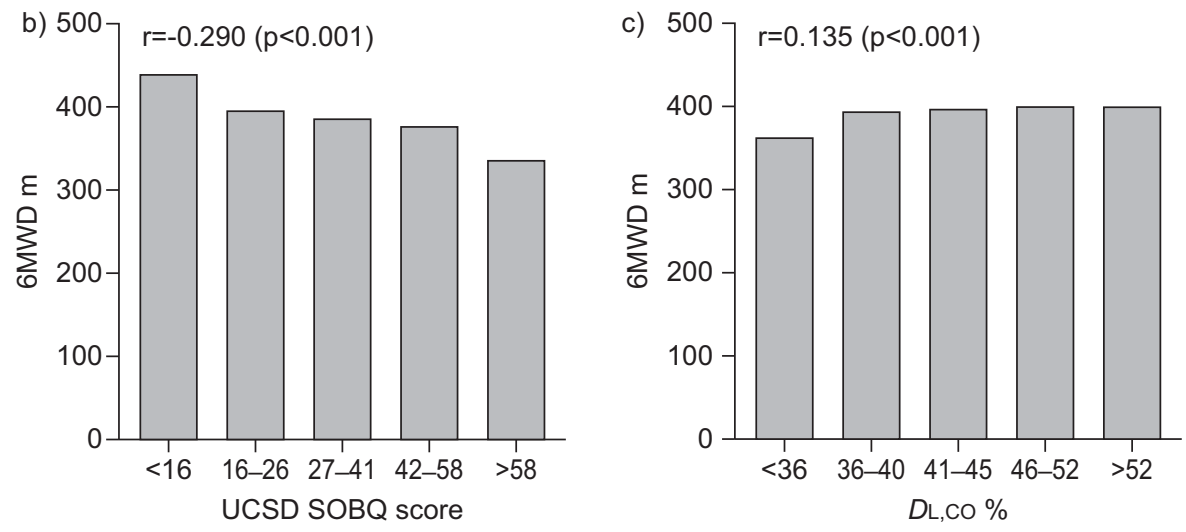

FIGURE 1. Validity correlations between 6-min walk distance (6MWD) and other functional parameters. FVC: forced vital capacity; UCSD SOBQ: University of California, San Diego, Shortness of Breath Questionnaire; DL,CO: diffusing capacity of the lung for carbon monoxide; SGRQ: St George's Respiratory Questionnaire. Data taken from [24]. a 24-week decrement of $>50 \mathrm{~m}$ was associated with a four-fold increase in the risk of death over the subsequent 12 months $(\mathrm{p}<0.001)$ [23].

The validation of a simple, reproducible measure of outcome in a mortality scoring system is an important but challenging task. A mortality risk scoring model for patients with $1 \mathrm{PF}$ was recently provided by DU BoIs et al. [35]. The proposed abbreviated clinical model comprises four readily available clinical measures of disease status (age, FVC at baseline, 24-week change in FVC and 24-week history of respiratory hospitalisation) that reliably predict 1-yr mortality in patients with IPF. This simplified scoring system may be a valuable tool for determining mortality risk of IPF patients in clinical practice, facilitating clinical decision making in the management of patients with IPF [35].

\section{Sensitivity to treatment effect}

VALEYRE et al. [36] have assessed the longitudinal change in FVC and $6 \mathrm{MWT}$ in pooled pirfenidone $2,403 \mathrm{mg} \cdot \mathrm{day}^{-1}(\mathrm{n}=345)$ and placebo $(n=347)$ groups from the CAPACITY trials. FVC and $6 \mathrm{MWT}$ distance were measured at baseline and at 12-week intervals until week 72. The pattern of change over time in FVC and 6MWT in the two groups was found to be very similar (fig. 3). The treatment effect for both outcome measures was evident at week 12, reached a peak at week 36 and persisted through week 72. However, the correlation at week 72 across these two measurements in individual patients was weak $\left(\mathrm{r}^{2}=0.10\right.$ for both groups), suggesting that these outcomes measure different functional domains of the IPF disease process [36].

\section{COMPOSITE END-POINTS}

Composite end-points take two or more outcome measures and combine them into a single outcome measure [37]. Composite end-points have been used to increase the overall event rate and thereby reduce the number of patients needed for a clinical trial. A well-designed and validated composite end-point can provide a reliable means of testing new treatments using a trial of relatively short duration [38]. A composite end-point may also address the issue of multiplicity (no adjustment to type 1 error required), may help to assess the "net effect" of treatment, and can be a useful support for the choice of a primary end-point [37, 38]. A composite end-point should meet the following criteria: each component is clinically meaningful and biologically plausible; each component is sensitive to treatment; the expected treatment effect on each component is similar; and each component can be analysed and reported individually [39]. A composite end-point that includes measures of outcome clearly related to the mortality risk seems to be one of the more reliable end-points for IPF clinical studies. Thus, progression-free survival, the end-point usually employed for lung cancer (a disease whose biology is in some respects similar to that of IPF) [40-42], could potentially be suggested as an optimal composite end-point for IPF. 

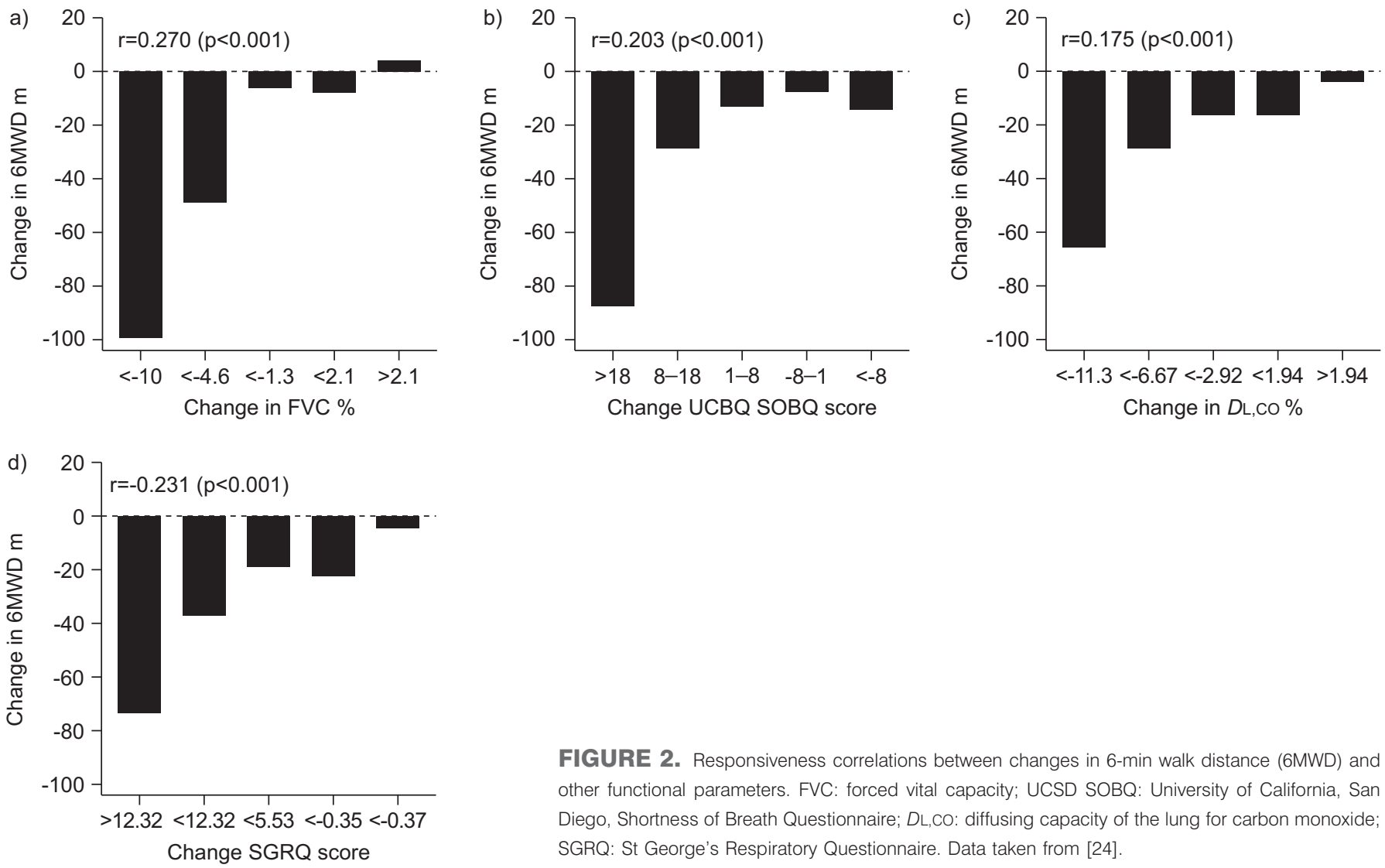

FIGURE 2. Responsiveness correlations between changes in 6-min walk distance (6MWD) and other functional parameters. FVC: forced vital capacity; UCSD SOBQ: University of California, San Diego, Shortness of Breath Questionnaire; $D \mathrm{~L}, \mathrm{CO}$ : diffusing capacity of the lung for carbon monoxide; SGRQ: St George's Respiratory Questionnaire. Data taken from [24].

\section{CONCLUSION}

The clinical course of IPF is variable and its natural history poses many challenges for clinical research. Investigators involved in the planning of IPF clinical studies face considerable challenges in selecting outcome measures that will allow statistical assessment of clinically meaningful effects or outcomes. A number of clinical and surrogate end-points have been proposed and evaluated in studies. Changes in FVC and
6MWT have been found to be reliable, valid and responsive clinical outcome measures in patients with IPF. Mortality, the ideal and most compelling primary end-point, can be useful but is challenging to study requiring large cohorts of patients and long-lasting studies. Since there is increasing evidence indicating that the fundamental hallmarks of cancer biology are comparable to those of IPF, the primary end-point of progression-free survival, which is usually employed for lung
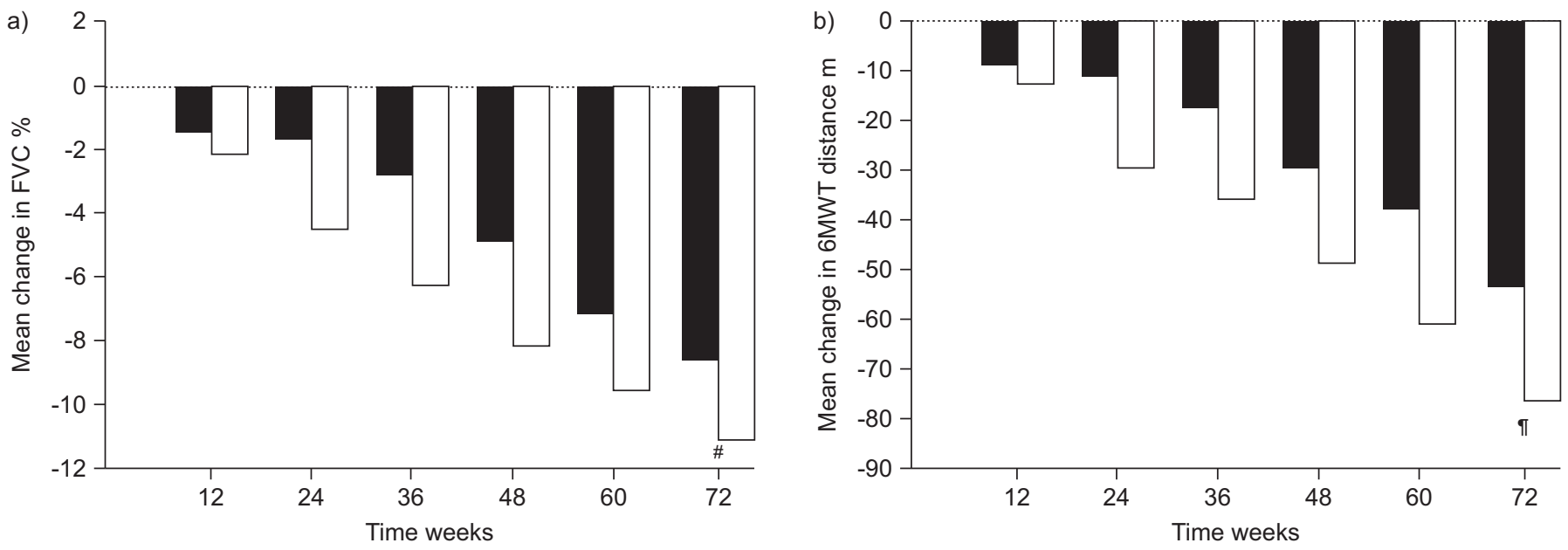

FIGURE 3. The pattern of change over time (72 weeks) in a) forced vital capacity (FVC) and b) 6-min walk test (6MWT) in patients receiving pirfenidone ( $\square$ : $n=345)$ or placebo ( $\mathbf{\square}: n=347) .{ }^{*}: p=0.005 ; ": p=0.001$. Adapted from [36]. 
cancer, could be potentially suggested as an end-point for IPF. The predictive value of easily measured and reliable clinical and physiological variables could improve the care of patients with IPF. However, more studies are needed to improve treatment of IPF with current and new compounds, alone or in combination.

\section{STATEMENT OF INTEREST}

C. Albera has acted as a speaker and a consultant for InterMune Inc. and has received fees of less than $€ 5,000$ in the past year.

\section{ACKNOWLEDGEMENTS}

This article is based on the proceedings of a satellite symposium held at the 2010 ERS Annual Congress (Barcelona, Spain), which was sponsored by InterMune Inc. The author was assisted in the preparation of the text by professional medical writers at IntraMed International (Milan, Italy). The medical writing support was funded by InterMune Inc.

\section{REFERENCES}

1 du Bois RM, Albera C, Bradford WZ. Predictors of mortality in patients with idiopathic pulmonary fibrosis (IPF). Am J Respir Crit Care Med 2009; 179: A1114.

2 American Thoracic Society. Idiopathic pulmonary fibrosis: diagnosis and treatment. International consensus statement. American Thoracic Society (ATS), and the European Respiratory Society (ERS). Am J Respir Crit Care Med 2000; 161: 646-664.

3 De Vries J, Kessels BL, Drent M. Quality of life of idiopathic pulmonary fibrosis patients. Eur Respir J 2001; 17: 954-961.

4 American Thoracic Society, European Respiratory Society. American Thoracic Society/European Respiratory Society International Multidisciplinary Consensus Classification of the Idiopathic Interstitial Pneumonias. Am J Respir Crit Care Med 2002; 165: 277-304.

5 Martinez FJ, Safrin S, Weycker D, et al. The clinical course of patients with idiopathic pulmonary fibrosis. Ann Intern Med 2005, 142: 963-967.

6 Albera C, du Bois RM, Bradford WZ. Prognostic significance of surgical lung biopsy (SLB) in a well-characterized cohort of patients with idiopathic pulmonary fibrosis (IPF). Am J Respir Crit Care Med 2010; 181: A2971.

7 King TE Jr, Safrin S, Starko KM, et al. Analyses of efficacy end points in a controlled trial of interferon- $\gamma 1 \mathrm{~b}$ for idiopathic pulmonary fibrosis. Chest 2005; 127: 171-177.

8 Azuma A, Nukiwa T, Tsuboi E, et al. Double-blind, placebocontrolled trial of pirfenidone in patients with idiopathic pulmonary fibrosis. Am J Respir Crit Care Med 2005; 171: 1040-1047.

9 Raghu G, Brown KK, Bradford WZ, et al. A placebo-controlled trial of interferon $\gamma-1 \mathrm{~b}$ in patients with idiopathic pulmonary fibrosis. N Engl J Med 2004; 350: 125-133.

$10 \mathrm{du}$ Bois RM. Is idiopathic pulmonary fibrosis now treatable? Am J Respir Crit Care Med 2005; 171: 939-940.

11 Noble PW, Albera C, Bradford WZ, et al. Pirfenidone in patients with idiopathic pulmonary fibrosis (CAPACITY): two randomised trials. Lancet 2011; 377: 1760-1769.

12 Taniguchi H, Ebina M, Kondoh Y, et al. Pirfenidone in idiopathic pulmonary fibrosis. Eur Respir J 2010; 35: 821-829.

13 Daniels CE, Lasky JA, Limper AH, et al. Imatinib treatment for idiopathic pulmonary fibrosis: randomized placebo-controlled trial results. Am J Respir Crit Care Med 2010; 181: 604-610.

14 King TE Jr, Albera C, Bradford WZ, et al. Effect of interferon $\gamma-1 b$ on survival in patients with idiopathic pulmonary fibrosis (INSPIRE): a multicentre, randomised, placebo-controlled trial. Lancet 2009; 374: 222-228.

15 Raghu G, Brown KK, Costabel U, et al. Treatment of idiopathic pulmonary fibrosis with etanercept: an exploratory, placebocontrolled trial. Am J Respir Crit Care Med 2008; 178: 948-955.
16 King TE Jr, Behr J, Brown KK, et al. BUILD-1: a randomized placebo-controlled trial of bosentan in idiopathic pulmonary fibrosis. Am J Respir Crit Care Med 2008; 177: 75-81.

17 Kubo H, Nakayama K, Yanai M, et al. Anticoagulant therapy for idiopathic pulmonary fibrosis. Chest 2005; 128: 1475-1482.

18 Demedts M, Behr J, Buhl R, et al. High-dose acetylcysteine in idiopathic pulmonary fibrosis. N Engl J Med 2005; 353: 2229-2242.

19 Karimi-Shah BA. Pulmonary-Allergy Drugs Advisory Committee Meeting. Pirfenidone capsules NDA 22-535, S-000. U.S. Food and Drug Administration. www.fda.gov/downloads/Advisory Committees/CommitteesMeetingMaterials/Drugs/PulmonaryAllergyDrugsAdvisoryCommittee/UCM206398.pdf

20 ATS Committee on Proficiency Standards for Clinical Pulmonary Function Laboratories. ATS statement: guidelines for the sixminute walk test. Am J Respir Crit Care Med 2002; 166: 111-117.

21 Eaton T, Young P, Milne D, et al. Six-minute walk, maximal exercise tests: reproducibility in fibrotic interstitial pneumonia. Am J Respir Crit Care Med 2005; 171: 1150-1157.

22 Snow JL, Kawut SM. Surrogate end points in pulmonary arterial hypertension: assessing the response to therapy. Clin Chest Med 2007; 28: 75-89, viii.

23 du Bois RM, Weycker D, Albera C, et al. Six minute-walk test in idiopathic pulmonary fibrosis: test validation and minimal clinically important difference. Am J Respir Crit Care Med 2011; 183: 1231-1237.

24 du Bois RM, Albera C, Bradford WZ, et al. Percent predicted forced vital capacity (FVC) is a reliable valid and responsive measure of clinical status in patients with idiopathic pulmonary fibrosis (IPF). Eur Respir J 2010; 36: Suppl. 54, 646s.

25 Jaeschke R, Singer J, Guyatt GH. Measurement of health status Ascertaining the minimal clinically important difference. Control Clin Trials 1989; 10: 407-415.

26 Latsi PI, du Bois RM, Nicholson AG, et al. Fibrotic idiopathic interstitial pneumonia: the prognostic value of longitudinal functional trends. Am J Respir Crit Care Med 2003; 168: 531-537.

27 Collard HR, King TE Jr, Bartelson BB, et al. Changes in clinical and physiologic variables predict survival in idiopathic pulmonary fibrosis. Am J Respir Crit Care Med 2003; 168: 538-542.

28 Flaherty KR, Mumford JA, Murray S, et al. Prognostic implications of physiologic and radiographic changes in idiopathic interstitial pneumonia. Am J Respir Crit Care Med 2003; 168: 543-548.

29 Jegal Y, Kim DS, Shim TS, et al. Physiology is a stronger predictor of survival than pathology in fibrotic interstitial pneumonia. Am J Respir Crit Care Med 2005; 171: 639-644.

30 Lama VN, Flaherty KR, Toews GB, et al. Prognostic value of desaturation during a 6-minute walk test in idiopathic interstitial pneumonia. Am J Respir Crit Care Med 2003; 168: 1084-1090.

31 Caminati A, Bianchi A, Cassandro R, et al. Walking distance on 6MWT is a prognostic factor in idiopathic pulmonary fibrosis Respir Med 2009; 103: 117-123.

32 Lederer DJ, Arcasoy SM, Wilt JS, et al. Six-minute-walk distance predicts waiting list survival in idiopathic pulmonary fibrosis. Am J Respir Crit Care Med 2006; 174: 659-664.

33 Lynch DA, Godwin JD, Safrin S, et al. High-resolution computed tomography in idiopathic pulmonary fibrosis: diagnosis and prognosis. Am J Respir Crit Care Med 2005; 172: 488-493.

34 Flaherty KR, Thwaite EL, Kazerooni EA, et al. Radiological versus histological diagnosis in UIP and NSIP: survival implications. Thorax 2003; 58: 143-148.

35 du Bois RM, Weycker D, Albera C, et al. Ascertainment of individual risk of mortality for patients with idiopathic pulmonary fibrosis. Am J Respir Crit Care Med 2011; [Epub ahead of print DOI: 10.1164/rccm.201011-1790OC].

36 Valeyre D, Albera C, du Bois RM. 6 minute walk distance (6MWD) and forced vital capacity (FVC) in patients with idiopathic pulmonary fibrosis (IPF): similar pattern of pirfenidone response. Am J Respir Crit Care Med 2010; 181: A6026. 
37 International Conference on Harmonisation of Technical Requirements for Registaration of Pharmaceuticals for Human Use. ICH Harmonised Tripartite Guideline. Statistical Principals For Clinical Trials E9. Current step 4 version. February 5, 1998. www. ich.org/fileadmin/Public_Web_Site/ICH_Products/Guidelines / Efficacy/E9/Step4/E9_Guideline.pdf

38 Cannon CP. Clinical perspectives on the use of composite endpoints. Control Clin Trials 1997; 18: 517-529.

39 The European Agency for the Evaluation of Medicinal Products. Evaluation of Medicines for Human Use. Committee for Proprietary Medicinal Products (CPMP). Points to Consider on
Multiplicity Issues in Clinical Trials. September 19, 2002. www. tga.gov.au/docs/pdf/euguide/ewp/090899en.pdf

40 Reck M, von Pawel J, Zatloukal P, et al. Phase III trial of cisplatin plus gemcitabine with either placebo or bevacizumab as first-line therapy for nonsquamous non-small-cell lung cancer: AVAil. J Clin Oncol 2009; 27: 1227-1234.

41 Mok TS, Wu YL, ThongprasertS, et al. Gefitinib or carboplatin-paclitaxel in pulmonary adenocarcinoma. N Engl J Med 2009; 361: 947-957.

42 Vancheri C, Failla M, Crimi N, et al. Idiopathic pulmonary fibrosis: a disease with similarities and links to cancer biology. Eur Respir J 2010; 35: 496-504. 